\title{
Assessment of the business potential impact on the controllability of an investment- construction project
}

\author{
Svetlana Sheina ${ }^{1, *}$, Natalya Tsopa ${ }^{2}$, and Lubov Kovalskaya ${ }^{2}$ \\ ${ }^{1}$ Don State Technical University, Academy of Construction and Architecture, Rostov-on-Don, Russia \\ ${ }^{2}$ V.I.Vernadsky Crimean Federal University, Academy of Construction and Architecture, Simferopol, \\ Russia
}

\begin{abstract}
The article discusses the important applied problem dedicated to the theoretical and methodological justification for assessing the impact of business potential on the controllability of an investment-construction project. It is proved that the business potential of the investmentconstruction project characterizes its potential managing opportunities. In the article the terms of the theory of controlled development of investmentconstruction projects are formalized. Business potential of the project is considered as a set of four components: organizationally-technological, economic, financial and human resources. In order to determine the level of controllability of the investment-construction project business potential, an algorithm was developed for assessing the project. This algorithm involves four basic stages: preparation, application development, analytical and operational stages. The algorithm developed in the article was approved by an example of the project for the construction of a car showroom. The level of investment-construction project business potential sustainability is defined by a special scale. The results of the project business potential assessment allow to make target regulation solutions for the project development.
\end{abstract}

\section{Introduction}

Transition to the managed sustainable development of various objects, including investment-construction projects as the main element of the construction organization, is very relevant and necessary in modern conditions. It should be noted that in the theory of management of technical systems, the distinction between subjects and objects of management is clearly traced. Also in this theory the concept of controllability is connected with the concept of management. This concept "... is related to the transfer (transition) of the system from one state to another by means of management. In other words, "controllability is a property of a control system that describes an opportunity to transfer systems from one state to another" [1]. In this context, controllability characterizes the potentialities of an investment-construction project to implement management. Business

\footnotetext{
* Corresponding author: rgsu-gsh@mail.ru
} 
potential of the investment-construction project also characterizes its potential for management. Accordingly, it is necessary to ensure stability of the investment-construction project to increase the degree of its controllability.

\section{Materials and methods}

In scientific publications devoted to the problems of project management, several methodological approaches to determining the place and value of controllability in the development management system have been found [2-8]. So, from system-wide positions, development is considered as the change type raising the degree of the system organization. Formally, development can be considered as controlled and achieved through selforganization.

Development through self-organization is ensured by the activity of elements that make up the structure of the investment-construction project [2-4].

Another approach to determining the place and meaning of self-organization in the development system is proposed [3-5]. Self-organization in the development system is ensured by optimal dosing of control actions for the purpose of keeping stability.

In the work [6, 7] it was noted that controlled project development involves the allocation of a system in which all processes leading to a change in the composition, properties, structure of relationships and relations of the constituent elements of the production system are combined: innovation processes integrated into development programs; growth of a construction company; reengineering of business processes of the enterprise; processes of restructuring and privatization of enterprises; processes of crisis development and crisis management of the enterprise leading to quantitative and qualitative changes in all functional areas of the production and economic system, as well as the contours of its management based on feedback in which the tasks of strategic and tactical management are being solved and the mechanisms for self-organization of operational management of the development of a construction enterprise.

Some authors [8] understand controlled development taking into account the control actions in the direction of a given goal.

It should be noted that despite the sufficient researches devoted to sustainable development, assessment of business potential impact on controllability of the investmentconstruction project wasn't conducted. Therefore, this research is rather relevant and timely.

The purpose of this research is the theoretical and methodological justification for assessing the impact of business potential on controllability of the investment-construction project. Within the framework of the set goal, the following tasks were solved in the article: the conceptual-terminological terms were formalized; the recommended algorithm for assessing business potential of the investment-construction project (ICP) was developed; its approbation was conducted and the level of sustainability of ICP business potential was determined.

\section{Results}

To assess the impact of business potential on controllability of the investment-construction project, it is necessary to formalize the research conceptual terms.

Under the controlled development of the project, within the framework of this research, we understand such a development in which systemic control actions take place aimed at improving the quality of project implementation depending on the stages (phases) of its development. 
Now we will formalize the notion of controllability of an investment-construction project, under which in this paper we understand the goal-oriented regulation of project development.

An adequate criterion for making investment decisions in business is business potential of an investment-construction project that can be presented as a complex multifactor quantitative and qualitative characteristic of the state of the investment-construction project key components that reflects the degree of attractiveness of the investment project for its funding. The business potential of the investment project also serves as a basis for recommendations for further support in the process of its implementation [9].

The analysis of approaches to a concept business potential of ICP showed that the necessary components of the business potential of the ICP for the purpose of justifying their financing is the organizationally-technological potential, economic, financial (tax) and human resources. Analysis of approaches to the concept of the ICP business potential showed that the necessary components of the ICP business potential for the purpose of justifying their financing are the organizational and technological potential, as well as economic, financial (taxation) and human resources.

For ICP business potential assessment, we offer an algorithm which will allow to define the systemic control actions aimed at improving the quality of project implementation. This algorithm includes four main stages: preparatory, analytical, operational and the stage of applied developments.

At the preparatory stage, the baseline data are collected for each component of the business potential, the prerequisites for the formation of its competitiveness are considered, the ICP aim and objectives are determined.

To assess the identified four components of the business potential of ICP: organizational, technological, economic, financial (taxation) and human resources, the initial data were determined that serve to analyze the prerequisites for the formation of competitiveness of ICP business potential. The source of data collection was the data obtained during the implementation of the ICP.

Based on the considered prerequisites for the formation of competitive ICP business potential, its goals and objectives are formed, the main one being to increase the degree of project controllability in order to increase the project's competitiveness among other projects.

The second stage is the stage of application development, during which tools are being developed for the formation of a competitive ICP business potential, i.e. the ICP itself is developed and implemented, the inherent risks are identified.

The next stage is the analytical stage, the purpose of which is to assess the level of use of business potential. To do this, first, an assessment of the components of the potential is conducted, based on the formation of groups of indicators to analyze each component of the business potential. The initial data in assessing the organizational and technological potential are the factors that have the greatest impact on the formation of this potential, among them the availability of temporary buildings and structures on the construction site, vertical and horizontal transport, and lighting of the construction site [10-12]. When assessing the economic potential of the ICP, it is proposed to use indicators for evaluating the effectiveness of the project. Since the assessment of the effectiveness of the ICP is based on a system of indicators that measures the effect of the project with its investment costs, the effect is presented in the form of cash flows generated, which are understood as the sum of time-allocated receipts and payments from the implementation of the investment project.

According to the methodology of the International Bank for Reconstruction and Development, among modern methods of estimating the effectiveness of ICP using the time factor method, two groups can be distinguished in the calculations: static and dynamic. The 
most popular dynamic indicators of efficiency assessment for investment projects are: NPV (Net Present Value); IRR (Internal Rate of Return); PI (Profitability Index); PP (Payback Period).

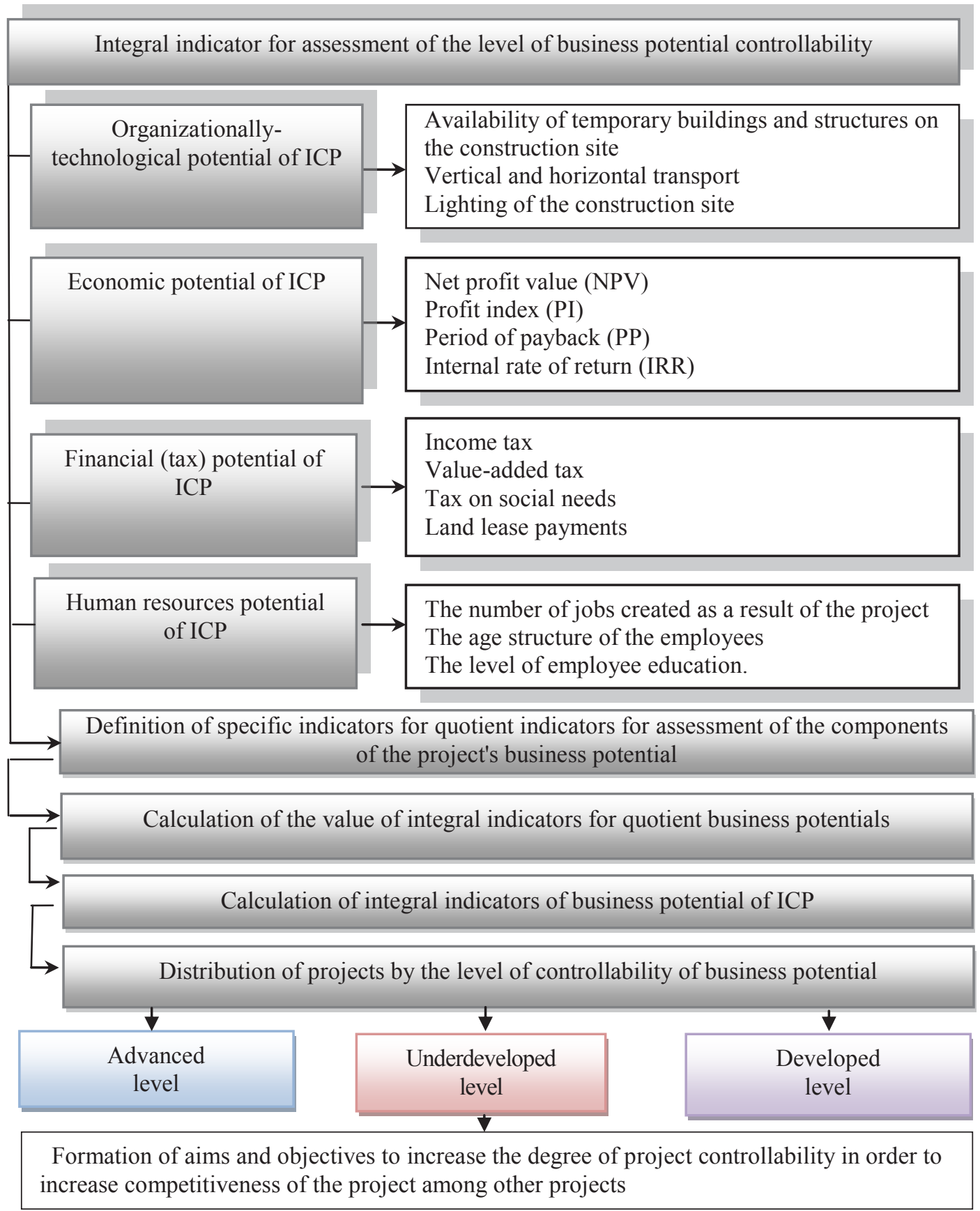

Fig. 1. Stages for assessing the level of controllability of the ICP business potential 
Under the financial (tax) potential, we will understand the maximum possible amount of revenues from taxes and fees, calculated in the current legislation during realization of ICP. As the main indicators of the financial (tax) potential of the ICP, it is proposed to use the income tax, value-added tax, tax on social needs and land lease payments.

To assess the human resources potential, it is proposed to take into account the number of jobs created as a result of the project, as well as the age structure and level of education of the employee.

Based on the study of data on all components of the business potential, the level of sustainability of ICP business potential is defined. After this, an integral assessment of the level of use of ICP business potential is conducted. The purpose of such assessment is to study the four components of the potential (organizationally-technological, economic, financial (tax) and human resources) by calculating an integral indicator that characterizes the level of sustainability of ICP business potential. Creation of the integral indicator is based on the method of calculating the arithmetic mean. The main goal of the assessment is to determine the level of sustainability of the ICP business potential, to justify and find ways to increase or maintain its competitiveness.

The fourth stage is final, it is the operational stage. This stage is based on the assessment of the level of business potential of the ICP usage. It should determine the competitive advantages and form the directions for developing the ICP business potential and select strategic directions for developing business potential for increasing the ICP controllability.

Approbation of the algorithm for assessing the ICP business potential was conducted on the example of the investment-construction project of a car showroom.

The project involves the construction of commercial facilities for the purpose of their subsequent operation. The volume of investments in the project is $17,825,140$ rubles, the term of realization is 11 years. The following calculated values of social and economic efficiency indicators of this investment project were obtained: NPV - 203152,42 thousand rubles, PI - 113,9\%, PP - 0,81 years, IRR - 16,71, number of jobs created - 15 .

Analysis of approaches to business potential assessment revealed an objective need for improvement of the approach to assessing the sustainability of business potential by using more detailed indicators. Figure 1 presents the recommended sequence of steps for assessing the level of sustainability of the ICP business potential.

Integrated assessment of investment-construction project business potential consists of assessment for four main components: organizational-technological, economic, financial and human resources potentials. For each of these potentials, the baseline data are determined that serve to analyze the prerequisites for the competitiveness of the ICP business potential. The source of data collection is the data obtained during the ICP realization.

\section{Discussion}

The integral indicator of assessment of investment-construction project business potential proposed by us in this article is based on taking into account all four components of ICP business potential, giving a description of the ICP position from the point of view of economic stabilization and about the "threshold" values of economic security, calculated by the formula [13]:

$$
\begin{gathered}
U=\sum U_{i} \\
U_{i}=K_{i} \frac{P_{i}}{N p_{i}}
\end{gathered}
$$


$\mathrm{Ki}$ - coefficient of the importance of an i quotient;

$\mathrm{Pi}$ - actual value of an i quotient;

Npi - normative value of an i quotient.

Using this formula and defining the methodological basis for assessing the business potential of ICP, we calculated the values of the integral indicator of the ICP business potential, Figure 2-3. The differences in these options are in the sales volume of cars: at the basic scenario, $100 \%$ of sales - 36 domestic and 24 foreign cars, at the optimistic scenario, sales are expected to increase to $110 \%-40$ and 26 cars respectively, at the pessimistic scenario, sales are expected to fall to $90 \%-32$ and 22 cars.

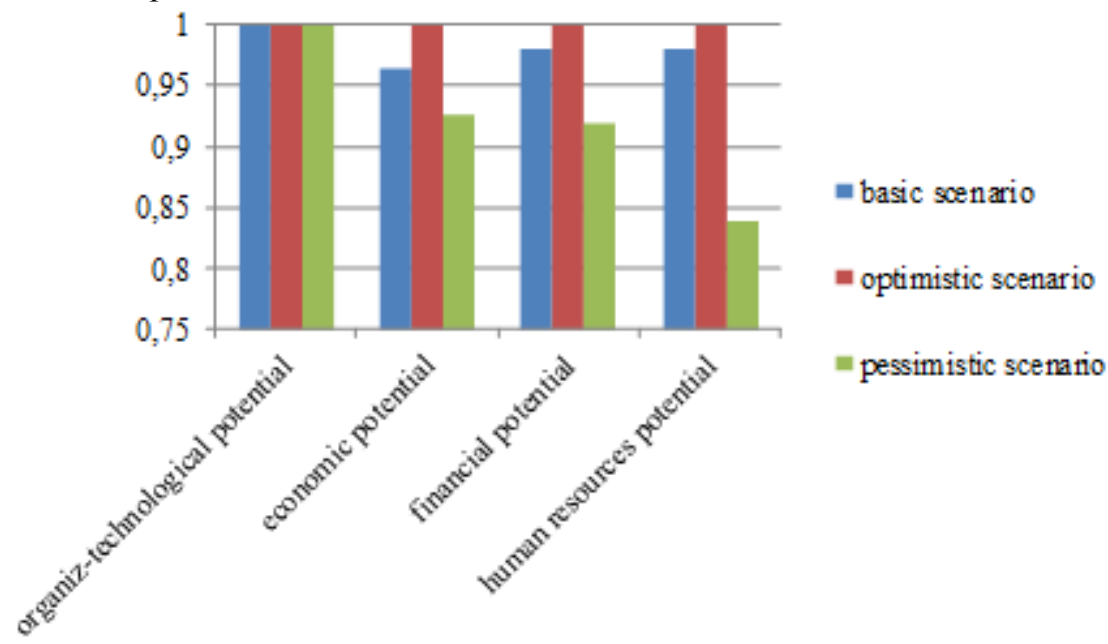

Fig. 2. Results of assessing components of ICP business potential

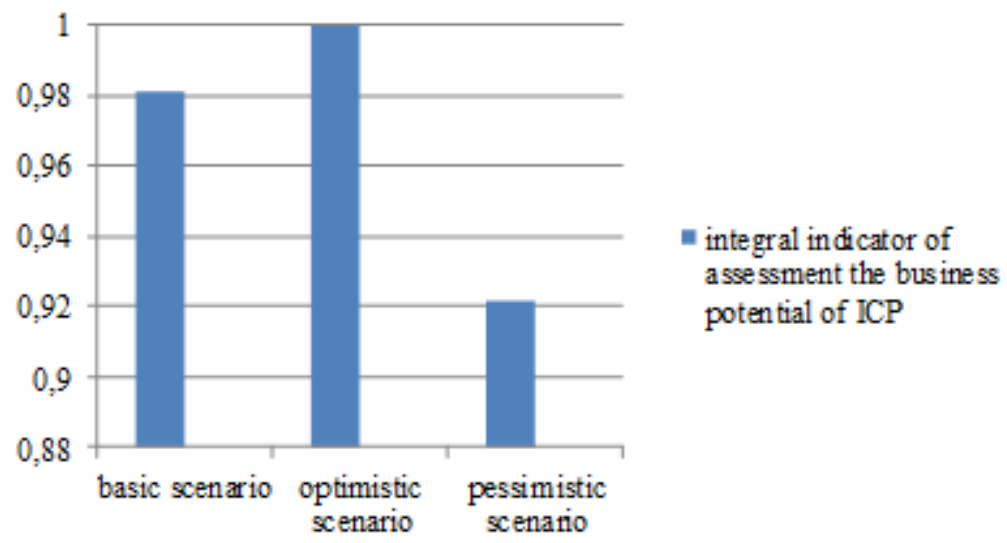

Fig. 3. The integral indicator of assessment sustainability of the business potential of the investmentconstruction project

For determination of the level of sustainability of ICP business potential, the scale of its assessment is compiled. According to this scale, with the integral indicator of sustainability from 1 to 0.9 - the level of stability of business potential is estimated as highly developed, from 0.89 to 0.75 - developed, below 0.5 - underdeveloped level. The results of the 
assessment of the level of sustainability of ICP business potential showed (Figures 2-3) that when realizing the basic scenario of the ICP development, the integral index is higher than under the pessimistic scenario. Therefore, in our basic version, the project has a highly developed level of sustainability. If the potential of the project has an underdeveloped level of business potential development, then the main goals and objectives of the ICP are formed or revised, the main ones being to increase the degree of project controllability, in order to increase the project's competitiveness among other projects.

\section{Conclusions}

In this article the important applied problem is solved, dedicated to the theoretical and methodological justification for assessing the impact of business potential on the controllability of the investment-construction project. To determine the level of controllability of the ICP, an algorithm for assessing the business potential of the project was developed, which was tested on the example of an investment project for the construction of a car showroom.

The integral indicator of the business potential for investment-construction project is calculated, which is based on taking into account four components of the business potential of the project: organizationally-technological, economic, financial and human resources.

The level of sustainability of ICP business potential is defined by a special scale, which allows to determine the necessary measures for the goal-oriented regulation of project development.

\section{References}

1. A.A. Krasovskij, Reference book on the theory of automatic control (1987)

2. A.N. Asaul, V.P. Grahov, Integrative management in the investment and construction sphere (2007)

3. S.G. Sheina, Sustainable development of territories, cities and enterprises (2017)

4. N.V. Tsopa, About need of application risk - oriented methods for ensuring stability of the investment- construction project (Construction and industrial safety, 2017)

5. A.V. Leonov, A.Ju. Pronin, The role of self-organization in the innovative development of complex technical systems (Competence, 2017)

6. R.N. Lepa, Reflection of decision-making in the economy (Bulletin of the Ural Federal University, 2014).

7. V.A. Lefevre, Reflection (2003).

8. V.N. Burkov, The technology of creating effective socio-economic complexes on the basis of active design (Theory of active systems, 2001)

9. N.V. Tsopa, L.S. Kovalskaya, V.V. Malakhova, About need of assessment the territorial potential for effective management of municipality (Economy and ecology of territorial entities, 2017)

10. A.A. Lapidus, A.O. Fel'dman, Assessment of the organizational and technological potential of the construction project formed on the basis of information flows (Vestnik MSCU, 2015)

11. S.G. Sheina, E.N. Minenko, Technique of selection the organizational and technological resource-saving solutions in housing construction based on the multicriteria evaluation system (Housing construction, 2016)

12. A.A. Lapidus, L.P. Demidov, Investigation of factors influencing the index of the potential of the construction site (Vestnik MSCU, 2014) 
13. G.P. Gubanov, Methodical aspects of assessing the economic condition of the territory (2000) 